\title{
(110） SOIL-STRUCTURE INTERACTION OF A CONTAINMENT MODEL IN HUALIEN, TAIWAN
}

by

Todor Ganev ${ }^{1)}$, Fumio Yamazaki ${ }^{2)}$, Tsuneo Katayama ${ }^{3)}$ and Teruyuki Ueshima ${ }^{4)}$

\section{INTRODUCTION}

For observation of soil-structure interaction effects, a 1/4 scale nuclear reactor containment model has been constructed in Hualien, Taiwan in an active seismic zone on stiff soil [1]. The Hualien Large-Scale Seismic Test is an internationally sponsored project, developed as a continuation of the Lotung Large-Scale Seismic Experiment, which has been carried out on a soft soil site [2].

Obtaining soil-structure interaction data at a stiff soil site is necessary for validation of the technical basis for realistic approaches towards the problem. In contrast to the great variety of analytical and numerical approaches towards the dynamic soil-structure interaction problem, publicized data from observation of actual response of structures including free field motion and soil pressure are still relatively few.

The objective of this paper is to present results from forced vibration tests, microtremor observations and earthquake response analysis of the Hualien Model. A comparison with a similar study carried out by the present authors on a soft soil site in Japan [3] is offered.



a) Plan of the site

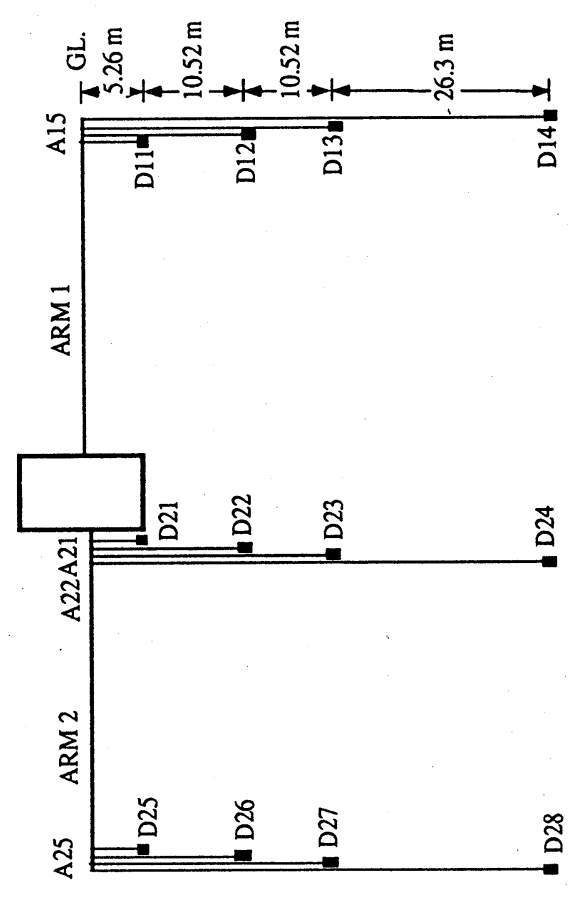

b) Vertical cross-section of the site

Figure 1. Locations of the accelerometers in the experiment site (all dimensions in $\mathrm{m}$ )

1) Graduate student, Civil Engineering Department, University of Tokyo.

2) Associate Professor, Institute of Industrial Science, University of Tokyo.

3) Professor, ditto

4) Research Fellow, Central Research Institute of Electric Power Industry (CRIEPI) 


\section{TESTS AND OBSERVATIONS AT THE HUALIEN SITE}

The properties of the soil around and beneath the structure have been systematically investigated by in-situ tests which comprise borings, large penetration tests and PS-loggings and laboratory tests which include triaxial tests on frozen undisturbed samples [4]. Based on the geotechnical investigation, the Central Research Institute of Electric Power Technology, Japan, created a soil model of the foundation ground [5]. This model was named "unified ground model" and the present analysis is based on it.

Two forced vibration tests have been conducted on the Hualien model: in October, 1992 before backfill (FVT-1) and in February, 1993 after backfill (FVT-2). Until this day, only results from analysis of FVT-1 have been officially publicized [6], [7].

Microtremors of the structure and the surrounding soil were recorded in October 1994, using simultaneously eight velocity-type pickups. As a very large peak, apparently due to signal or noise with unknown origin, appeared at frequency $1.5 \mathrm{~Hz}$ in the Fourier spectra of all the records, the data were filtered with a band-pass cosine-type filter from 2.0 to $25.0 \mathrm{~Hz}$.

At present, data from three earthquakes, recorded in 1994 are available: Event 940120 with peak ground acceleration $(\mathrm{PGA})=43 \mathrm{Gal}$, Event $940530, \mathrm{PGA}=34 \mathrm{Gal}$ and Event $940605, \mathrm{PGA}=42 \mathrm{Gal}$. The peak response acceleration, recorded at the roof top of the model structure is 74,38 and $64 \mathrm{Gal}$, respectively. Event 940530 caused a very small relative structural response.

\section{ORIENTATION ERRORS OF THE SEISMOMETERS}

The orientation of the accelerometers in the Hualien LSST site was verified using the maximum crosscorrelation method [8] on the basis of the currently available earthquake data. Point A15 (Figure 1) was chosen as a reference point. Figure 2 shows the definition of the orientation angles with respect to the geographical coordinate system. The orientation angles of the accelerometers in the backfill and on the structure displayed significant scattering, probably because of the structural response and its feedback on the backfill motion. For this reason, only the orientation errors of the free field accelerometers were determined conclusively. The calculated values of $\beta$ and $\gamma$ were scattered and in most cases less than 5 degrees so both $\beta$ and $\gamma$ were assumed to be null for all seismometers. Table 1 shows the values of $\alpha$ for the free field seismometers. It can be seen, that almost all the accelerometers have similar relative orientation. This indicates that actually the reference seismometer A15 has an orientation error with respect to the geographical coordinate system.

ANALYSIS OF OBSERVATION AND TEST DATA

Figure 3 presents a formal comparison between the results of FVT-2 and microtremor. The

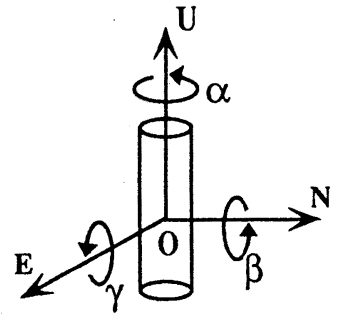

Figure 2. Definition of the rotation angles

\begin{tabular}{|l|r|}
\hline $\begin{array}{l}\text { Posi- } \\
\text { tion }\end{array}$ & $\begin{array}{c}\text { Angle } \\
\alpha[\mathrm{deg}]\end{array}$ \\
\hline A12 & 13.0 \\
A13 & 9.0 \\
A14 & 9.0 \\
D11 & 13.0 \\
D12 & 12.0 \\
$D 13$ & 13.0 \\
$D 14$ & 9.0 \\
$D 23$ & 16.0 \\
$D 24$ & 10.0 \\
$D 25$ & 12.0 \\
$D 26$ & 16.0 \\
$D 27$ & 14.0 \\
$D 28$ & 5.0 \\
\hline
\end{tabular}

Table 1. Rotation Angles

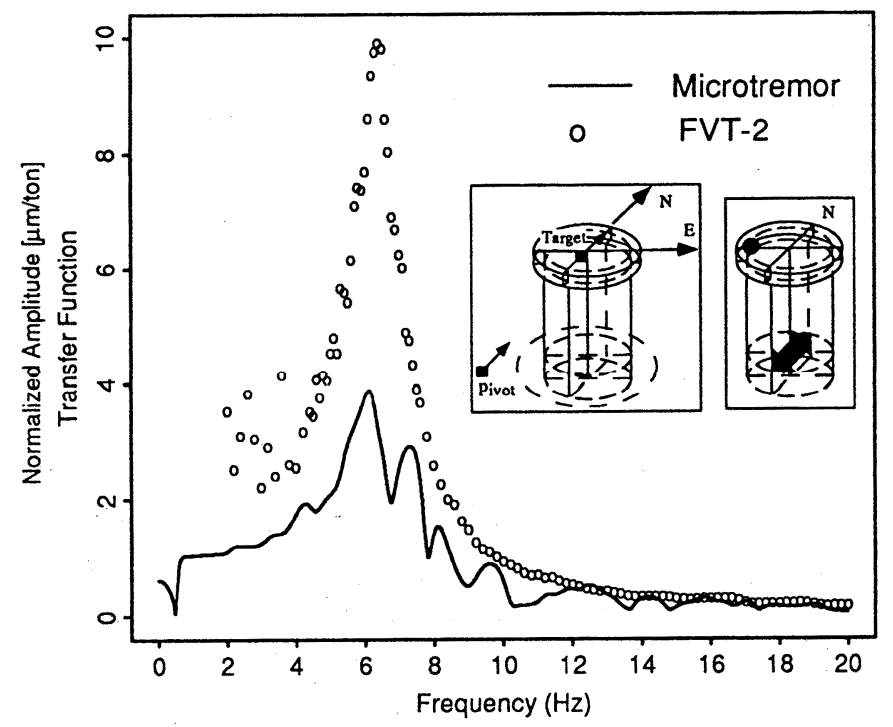

Figure 3. Formal comparison of microtremor with FVT-2 
predominant frequency of the system is evaluated as $6.4 \mathrm{~Hz}$ from FVT and 6.3 $\mathrm{Hz}$ from microtremor. This good agreement shows, that microtremor observation can be used successfully instead of forced vibration tests to evaluate system characteristics. Compared with the forced vibration tests, the microtremor observation is easy and inexpensive to perform. Also, from a theoretical point of view, microtremor is closer to earthquake excitation than FVT, and permits the same type of analysis.

Figure 4 shows transfer functions between the free field and the top of the structure, evaluated from observation data. It can be seen, that the predominant frequency of the system determined from microtremor $(6.3 \mathrm{~Hz})$ agrees well with the one, determined for the small earthquake Event $940530(6.2 \mathrm{~Hz})$. The predominant frequency determined by analysis of Event 940120 is $5.6 \mathrm{~Hz}$, about $10 \%$ less than the one for lowamplitude vibrations. Similar result was obtained from Event 940605 (Table 2).The reason for the shift of the predominant frequency is the weakening of the soil support during earthquakes. This phenomenon usually can be explained with three factors: soil nonlinearity, separation of soil from the structure and pore water pressure buildup. At this point, no clear evidence of separation or pore water pressure buildup has been obtained. Most probably, the soil stiffness degradation under dynamic loads is due to highly nonlinear behavior as a result of local stress concentration at the contact with the foundation.

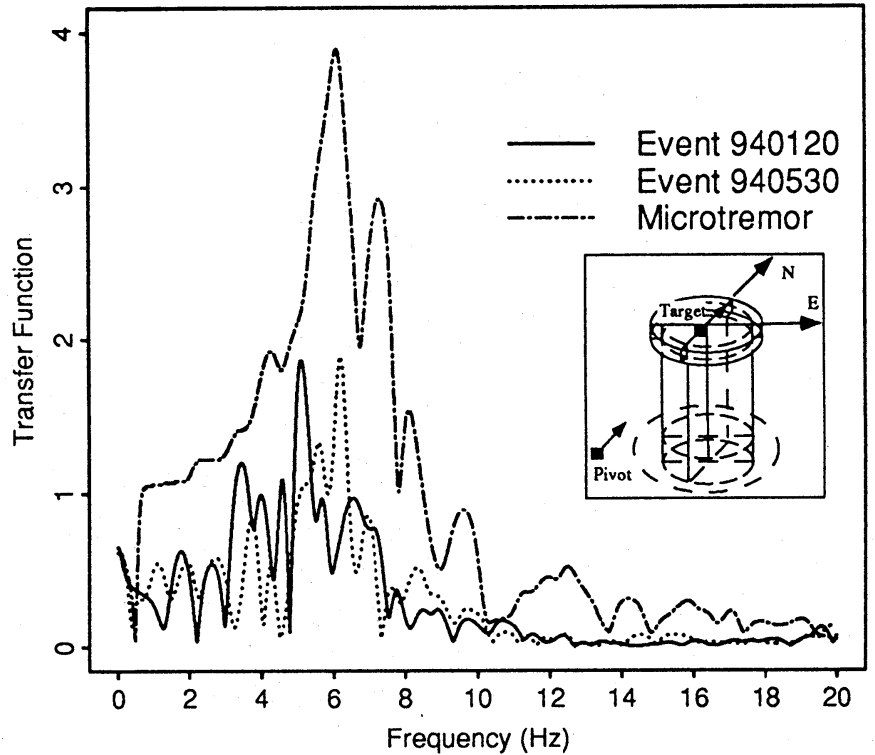

Figure 4. Transfer functions between the free field and the top

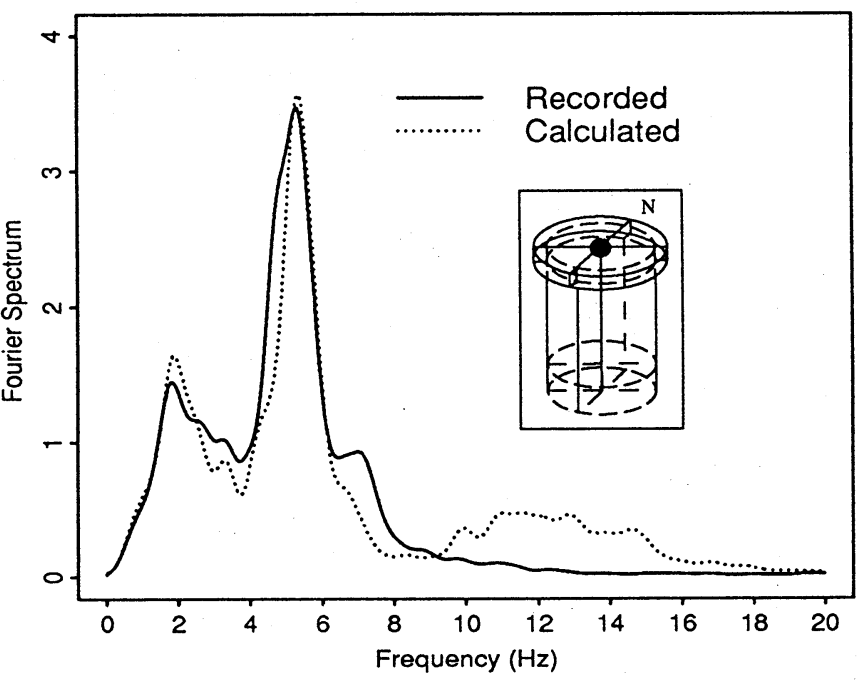

Figure 5. Fourier spectra of response at the roof top (Event 940120, NS-component)

\section{RESPONSE ANALYSIS OF THE SOIL-STRUCTURE SYSTEM}

The behavior of the soil-structure system was simulated using a linear sway-rocking model, according to the methodology described in [3]. The model represents the soil support by means of a rocking spring coefficient $K_{R}$, sway spring coefficient $K_{H}$, rocking dashpot coefficient $C_{R}$ and sway dashpot coefficient $C_{H}$. The values of these parameters were determined on the basis of the Continuum Formulation method [9] and the results of FVT-2, which represent a small-strain linear behavior, were successfully simulated. To account for the weakening of the soil support during each of the analyzed earthquakes, the soil coefficients were adjusted to fit the recorded response by the trial and error procedure, developed by Ganev et al. [3]. Good agreement between actual behavior and simulation was achieved in all cases. As an example, a comparison between the Fourier spectra of recorded and simulated response at the top of the structure during Event 940120 is presented in Figure 5. 
The values of the soil parameters, used Table 2. Best-fit values of the model soil parameters for the best-fit in each case are shown in Table 2. It can be seen, that compared to the case of FVT, which represents small strain behavior, the soil stiffness generally decreases during earthquakes. Event 940530 has a comparable PGA with the other two earthquakes, but unlike in their cases, the relative structural response is very small. Hence, the soil-structure interaction effects are not strong and the soil stiffness is close to the one evaluated for the FVT. The rocking spring constant decreases noticeably during different earthquakes, because the structural response is stron-

\begin{tabular}{|c|c|c|c|c|c|}
\hline \multirow{2}{*}{$\begin{array}{l}\text { Analyzed case } \\
\text { NS-direction }\end{array}$} & \multicolumn{2}{|c|}{$\begin{array}{l}\text { Soil spring } \\
\text { Coefficients }\end{array}$} & \multicolumn{2}{|c|}{$\begin{array}{l}\text { Soil dashpot } \\
\text { Coefficients }\end{array}$} & \multirow{2}{*}{$\begin{array}{c}\text { First } \\
\text { Natural } \\
\text { Frequency } \\
{[\mathrm{Hz}]}\end{array}$} \\
\hline & $\begin{array}{c}\mathrm{K}_{\mathrm{R}} \\
{[\mathrm{N} \cdot \mathrm{m} / \mathrm{rad}]} \\
\times 10^{11}\end{array}$ & $\begin{array}{c}\mathrm{K}_{\mathrm{H}} \\
{[\mathrm{N} / \mathrm{m}]} \\
\times 10^{11} \\
\end{array}$ & $\begin{array}{c}\mathrm{C}_{\mathrm{R}} \\
{[\mathrm{N} . \mathrm{ms} / \mathrm{rad}]} \\
\times 10^{11} \\
\end{array}$ & $\begin{array}{c}\mathrm{C}_{\mathrm{H}} \\
{[\mathrm{Ns} / \mathrm{m}]} \\
\times 10^{11}\end{array}$ & \\
\hline FVT-2 & 6.800 & 0.180 & 0.0300 & 0.0012 & 6.4 \\
\hline Event 940530 & 6.600 & 0.114 & 0.0055 & 0.00075 & 6.2 \\
\hline Event 940120 & 5.200 & 0.114 & 0.2250 & 0.0040 & 5.6 \\
\hline Event 940605 & 5.000 & 0.114 & 0.2000 & 0.0040 & 5.5 \\
\hline
\end{tabular}
ger and dominated by the rocking mode of motion. At the same time, the sway spring constant is one at the same at all the events, which can be related mainly to the similar amplitude of the ground motion. Compared to the results of FVT, the damping consistently increased during Events 940120 and 940605 . At this point, no conclusive explanation can be offered for the low damping during Event 940530.

The decrease of the soil stiffness is consistent with the results, obtained from analysis of a rigid tower on a soft soil site in Chiba, Japan [3]. In the case of soft soil, however, separation of soil from structure was detected and proven to be a more influential factor than nonlinearity. Unlike the stiff soil, the soft soil support exhibited a decrease in damping which again can be attributed to separation.

CONCLUSIONS

The dynamic behavior of a nuclear reactor containment model in Hualien, Taiwan was investigated, using data from forced vibration tests (FVT), microtremor observations and earthquake records. The response of the containment model to FVT and earthquakes was simulated successfully, using a linear sway-rocking model. By a comparative study of actual and calculated structural response it was found, that alterations in the soil support are very strongly dependent on the shape and amplitude of the structural motion. Those soil parameters, which are related to the dominant mode of the structural motion, are affected to a higher extent. Although the soil is rather stiff, even during a relatively small earthquake there is a significant weakening of the soil support. A comparison with previous research involving a similar structure on soft soil showed a decrease in soil stiffness during earthquakes in both cases, but the mechanism of soil stiffness degradation is different. The damping increases at the stiff soil site while it decreases at the soft soil site. The probable reason for this difference is that separation of soil from the structure occurred at the soft soil site, while such effect was not detected at the stiff soil site.

\section{REFERENCES}

[1] H. T. Tang, J. C. Stepp et al., "The Hualien Large Scale Seismic Test for Soil-Structure Interaction Research" Transactions of the $11^{\text {th }}$ International Conference on Structural Mechanics in Reactor Technology, Vol. K, pp. 69-74, Tokyo, Japan, 1991.

[2] EPRI. Proceedings: EPRIINRC/TPC Workshop on Seismic Soil-Structure Interaction Analysis Techniques Using Data from Lotung, Taiwan, Palo Alto, California, 1987.

[3] T. Ganev, F. Yamazaki, and T. Katayama, "Observation and Numerical Analysis of Soil-Structure Interaction of a Reinforced Concrete Tower", Earthquake Engineering and Structural Dynamics 24, pp. $491-503$ (1995)

[4] T. Kokusho, K Nishi, T. Okamoto, T. Kataoka, Y. Tanaka, K. Kudo, H. T. Tang and Y. H. Cheng, "Geotechnical Investigation in the Hualien Large Scale Seismic Test Project", Trans. $12^{\text {th }}$ Int. Conf. Str. Meck. in Reactor Technology, Vol. K1, Stuttgart, 1993. [5] T. Kokusho, K. Kudo, T. Okamoto, Y. Tanaka, T. Kawai, Y. Sawada, H. Yajima and K. Suzuki, "Soil-Structure Interaction Research of a Large-Scale Model Structure at Hualien, Taiwan (Part 1)" Proc. NinthJEES , Vol. 2, pp. 1369-1374, Tokyo, Japan, 1994.

[6] T. Ueshima, T. Kokusho, Y. Tanaka and N. Nakazono, "Soil-Structure Interaction Research of a Large-Scale Model Structure at Hualien, Taiwan (Part 2)", Proc. Ninth JEES ,Vol. 2, pp. 1375-1380, Tokyo, Japan, 1994.

[7] H. Morisita, H. Tanaka, N. Nakamura, T. Kobayashi, S. Kan, H. Yamaya and H. T. Tang, "Forced Vibration Test of the Hualien Large Scale SSI Model", Trans. $12^{\text {th }}$ Int. Conf. Str. Mech. in Reactor Technology, Vol. K02/1, pp. 37-42, Stuttgart, 1993.

[8] F. Yamazaki , L. Lu and T. Katayama, "Orientation Error Estimation of Buried Seismographs in Array Observation", Earthquake Engineering and Structural Dynamics, 21, pp. 679-694 (1992).

[9] T. Harada, K. Kubo and T. Katayama, 'Dynamic Soil-structure Interaction Analysis by Continuum Formulation Method', Report of the Institute of Industrial Science 29, University of Tokyo, 1981. 